\title{
Experiência Institucional
}

Resumo

$O$ artigo reflete sobre as atividades desenvolvidas em um projeto de pesquisa realizado na Universidade de São Paulo entre os anos de 2002 e 2007, enfocando em especial a modalidade de transferência que se desenvolveu na clínica com crianças diagnosticadas como autistas e as vicissitudes dai decorrentes, tendo por objetivo teorizar no campo da psicanálise de inspiração lacaniana.

Descritores: psicanálise; autismo; transferência; clínica psicanalitica.

\section{PARA CONCLUIR UM \\ PROJETO DE PESQUISA}

Jussara Falek

()

texto que aqui se inicia tem por objetivo transmitir a partir de uma teorização aquilo que foi adquirido na experiência do projeto TECER, projeto temático de pesquisa, realizado em equipe, que coordenei nos anos de 2002 a 2007 no Instituto de Psicologia da Universidade de São Paulo.

A boa palavra de Georges Perec (2009) permite-me situar bem a forma como aconteceu essa experiência:

Podemos deduzir daí algo que é, sem dúvida, a verdade última do puzzle: apesar das aparências, não se trata de um jogo solitário - todo gesto que faz o armador de puzzles, o construtor já o fez antes dele; toda peça que toma e retoma, examina, acaricia, toda combinação que tenta e volta a tentar, toda hesitação, toda intuição, toda esperança, todo esmorecimento foram decididos, calculados, estudados pelo outro. (p. 14)

Eu estava, como não poderia deixar de estar, imersa em um jogo de quebra-cabeças, quebrando a minha cabeça em busca de um desenho institucional que possibilitasse o atendimento psicanalítico, a inclusão clínica de crianças que haviam recebido um diagnóstico psiquiátrico de autismo. Tentando encaixar as peças em um quebra-cabeças bem mais amplo, fazer um acréscimo em um tecido 
que se estende para muito além do atendimento que eu procurava estabelecer.

A palavra de Perec permite também reafirmar, por outro lado, uma posição que não é minha, nem mesmo dele exclusivamente, mas que fala de um período na história do pensamento, e que se encontra também no texto de Lacan (1998b) quando ele define seu ponto de vista como psicanalista:

Designamos por letra este suporte material que o discurso concreto toma emprestado da linguagem. Essa definição simples supõe que a linguagem não se confunda com as diversas funções somáticas e psíquicas que a desservem no sujeito falante. Pela razão primeira de que a linguagem, com sua estrutura, preexiste à entrada de cada sujeito num momento de seu desenvolvimento mental. (p. 498)

E com isso reafirmo meu ponto de vista, demonstrado clinicamente em minha tese de livre-docência (Brauer, 2000), de que também no autismo estamos diante de um problema que se equaciona em termos de significante. Ideia que não é de minha autoria, que é defendida por $\operatorname{Lacan}^{1}$ e que sustenta a primazia do significante, também no caso de autismo.

Enuncio com essas duas citações o contexto teórico de onde parti neste projeto de pesquisa.

Importante é também reafirmar o entendimento que tenho de que o psicanalista não se ocupa do autismo. $\mathrm{O}$ autismo, já pela história desse termo, é em minha opinião, uma opção feita pela psiquiatria. Uma opção por tomar como objeto o corpo biológico ${ }^{2}$.

O psicanalista trabalha em outro registro. Ele posiciona-se na estrutura do sujeito, em $a$, e ocupa-se de dar a ver esse objeto que causa o sujeito: sua falta, seu desejo. Trabalha, portanto, no registro de um erotismo que se encontra por definição banido do campo da medicina e da ciência. Assim, trabalhamos com outra coisa muito diferente. Trabalhamos com outra teoria.

Uma teoria que supõe outro ponto de vista que adoto em minha investigação clínica, que a loucura é uma passagem humana, parafraseando Roland Léthier. Humana por ser atravessada pela palavra. Uma passagem que pode ser, em determinados casos, necessária. Não deve ser evitada. Uma passagem que produz uma pegada, um traço, que ao ser lido se completa, "resolve" a questão.

No campo em que trabalhamos não há o menor sentido em evitar a loucura, em curá-la, uma vez que ela já traz em seu bojo 
uma solução, que consiste na leitura do traço que essa passagem escreve. Trata-se então de criar condições para que essa solução seja alcançada.

Uma ideia, uma posição que concerne à psicanálise, desde Freud, e está presente na forma como ele define e entende o sintoma neurótico. Fácil dizer, difícil concretizar isso que digo.

O projeto TECER nasce dessa forma de ver a coisa. Ele vai trabalhar naquele espaço que foi deixado vazio pela intervenção do médico psiquiatra, pela escola que segue uma visão "medicalizada" da criança e pela sociedade sanitarista em que vivemos.

Nesse projeto, ocupamo-nos do jogo erótico estabelecido entre mãe e criança, tentando cultivar uma transferência, desviar a transferência selvagem das mães que era a princípio dirigida para a criança. Desviá-la na direção do analista que se ocupa do caso, clinicamente. E, ainda, criar com a criança uma transferência.

De nossa pesquisa anterior, concluída no ano 2000, sabíamos que quando esse trabalho consegue se realizar costuma ocorrer um efeito sobre a criança que, na maior parte das vezes, passa espontaneamente para outra coisa, engaja-se no mundo, apresentando aquilo que o meio vai acolher como uma "melhora" de seu estado.

No entanto há casos em que, em função do caminho feito anteriormente por aqueles que dessas crianças se ocuparam, elas encontram-se em um "impedimento". São crianças que não frequentam escola e que ficam assim "confinadas" no relacionamento familiar. Parti da hipótese de que era necessário tocar essa situação, intervindo no sentido de produzir as condições que eu considerava necessárias para a inclusão desses pacientes na escola, pois eu considerava que essa inclusão escolar poderia trabalhar em favor da superação dos problemas apresentados pela criança - esta foi a hipótese que originou esse projeto, coordenado por mim.

Criei, então, no interior do Instituto de Psicologia da Universidade de São Paulo (IP-USP), um espaço, um laboratório, onde os trabalhos deveriam se desenvolver. Nesse laboratório eu propunha uma estrutura de relacionamento não hierarquizado, que possibilitasse a participação de pessoas que tivessem níveis diferentes de formação: as crianças, alguns alunos de graduação, alguns alunos de pós-graduação, profissionais da psicologia, da educação, pós-graduandos em artes (música, cinema), todos reunidos em função de um interesse comum, que coincidiria com o objetivo que tínhamos no trabalho que desenvolveríamos ali: promover um espaço intermediário entre o trabalho clínico e a escolarização das crianças.

Alguns seriam então beneficiários do trabalho, outros seriam pesquisadores do processo, ou de algum ponto nele envolvido, outros estariam apenas interessados em realizar o trabalho. E haveria um tempo de duração 
para o trabalho, de seis anos, ditado pelo financiamento que eu havia obtido junto ao Fundo de Amparo à Pesquisa do Estado de São Paulo (FAPESP) para realizar esse projeto. Iniciamos os trabalhos em 2002, o financiamento foi aprovado em 2003 e foi utilizado de 2004 a 2007.

Pretendíamos trabalhar como um grupo, e o desafio foi justamente propiciar condições para que esse grupo pudesse acontecer. Seria um grupo no qual todos deveriam se incluir e, portanto, não apenas as crianças. Pois eu entendia que, tratando-se de crianças com um histórico de isolamento social, esse grupo só se formaria se nós todos fizéssemos um esforço nessa direção, seduzindo a criança de todas as formas, convidando-a enfim.

Esse trabalho ocorreria paralelamente ao atendimento clínico dessas crianças, que eram ouvidas por um profissional que escutava também a mãe da criança, em uma estratégia clínica pesquisada e relatada anteriormente, que foi objeto de minha livre-docência e da qual não me ocuparei aqui.

Finalizamos o projeto em um impasse importante ocasionado pela transferência que se desenvolveu na clínica, mas também no espaço de convivência e que se converteu em um fenômeno de grupo que não me foi possível manejar. É sobre esse mesmo ponto que retorno aqui, em busca de respostas para as muitas perguntas que o projeto TECER me trouxe.

\section{Resultados alcançados com o projeto TECER}

Diferentemente daquilo que me pareceu no término do projeto, em agosto de 2007, entendo hoje que o projeto foi bem-sucedido. Todos os envolvidos no projeto realizaram o trabalho de formação que os levou a trabalhar nele.

Conseguimos inserir seis (de um total de doze) crianças em classes normais e em classes especiais, e deixamos o caminho aberto para a inserção das demais. Em dois casos isso não foi possível, pois restava ainda um longo trabalho clínico a fazer.

Não pudemos atender 34 casos que se inscreveram em nosso projeto a partir do ano de 2005 por falta total de infraestrutura. Situação lamentável, mas que mostra que o projeto "pegou", e foi tomado como referência para a indicação de pacientes.

Foram defendidas seis dissertações de mestrado e duas teses de doutorado, fruto do trabalho desenvolvido em nosso laboratório, no prazo em que durou o projeto. Ainda hoje há teses nascidas ou desenvolvidas no laboratório que estão sendo concluídas.

Desenvolveram-se estágios de alunos de graduação e também de profissionais já experientes.

Esse trabalho ocorreu em um clima de grupo com a participação das crianças em uma posição diversa, nova para elas, pois no projeto TECER elas não eram pacientes. 
Nós conseguimos realizar o grupo que pretendíamos e inserir nossas crianças na vida escolar.

E houve, sim, muitos mal-entendidos, o preço a pagar pelo caminho que escolhemos, que toma partido do equívoco propiciado pela visada do significante. Não poderia ter sido diferente.

\section{Um trabalho que envolve profissionais de diferentes áreas}

Pode-se notar muito nitidamente, creio eu, que o trabalho que foi desenvolvido neste projeto não prescinde do trabalho (nem colide com ele) feito pela escola ou pelo médico que se ocupam da criança.

A proposta dessa forma de trabalho deve ser suportada, feita em colaboração com a escola e com os diversos profissionais que se ocupam de crianças e de suas necessidades. Creio também que esse tipo de trabalho possibilita um suporte para esses profissionais. Uma forma de trabalho deve se instituir no interior da rede social que se dedica ao cuidado da criança e de sua mãe, pois não se trata de um trabalho que vai atender a todas as necessidades apresentadas nesse campo.

Penso ainda que a duração limitada do trabalho está implícita no fato de que ele tem um objetivo claro: mediar o trabalho desenvolvido na clínica e a inserção da criança na escola, e oferecer um espaço para o desenvolvimento de estágios, de pesquisas, de mestrado e de doutorado. Tudo isso tem uma duração limitada, diferentemente do trabalho clínico, cuja duração é indeterminada.

\section{Da inclusão clínica}

Iniciei meu percurso como professora no ano de 1974, desenvolvendo minha clínica naquela que se denomina hoje clínica Durval Marcondes, ligada ao Departamento de Psicologia Clínica do Instituto de Psicologia da USP (IP -USP). Fundada por esse professor, que também ajudou a formar a Sociedade Brasileira de Psicanálise de São Paulo, essa clínica foi organizada segundo a doutrina freudiana.

Nela a prática era a seguinte: triavam-se entre os pacientes que procuravam por atendimento aqueles que seriam atendidos ali, e os neuróticos e os demais pacientes eram "encaminhados a outras instituições habilitadas ao seu atendimento", que não existiam naquela época. Assim, as crianças de que me ocupei como pesquisadora 
tinham como história clínica sucessivos trabalhos de diagnóstico e posterior encaminhamento. Jamais haviam recebido tratamento psicanalítico.

Jovem professora naquela época eu não concordava com essa prática, e considerava que não se devia fazer essa triagem, e como supervisora de estágio eu não o fazia. Com o tempo fui recebendo mais e mais crianças que apresentavam graves distúrbios, ao mesmo tempo em que ia iniciando esse percurso interminável de formação como analista, e desenvolvendo uma grande simpatia pela obra de Lacan. E foi nesse percurso que cheguei a desenvolver uma clínica voltada a essas crianças que apresentam distúrbios graves, dei aí os primeiros passos, encontrei grandes dificuldades e busquei na teoria lacaniana uma forma de dizer sobre essas dificuldades. Naquele tempo inicial de meu trabalho (Brauer, 1988) eu me atinha ao fundamento de que o sintoma apresentado pela criança teria que ser entendido como sintoma no sentido analítico do termo, deveria poder ser lida nele uma estrutura significante de metáfora. Eu fechava os olhos naquele momento para as ditas "condições de uma análise", que precisei retomar mais tarde, por ocasião do projeto TECER, pois foi somente aí que essa transferência, que de fato existe, como pude constatar, começou a apresentar sua face turbulenta.

O projeto TECER foi uma tentativa, malsucedida, de incluir clinicamente pacientes diagnosticados como autistas pela psiquiatria no âmbito da clínica Durval Marcondes. Consistiu em pesquisar uma estrutura institucional capaz de acolher esses pacientes.

Embora tenhamos conseguido realizar com sucesso esse atendimento, por razões exteriores ao nosso projeto, essa forma de tratamento que propusemos não chegou a se instituir na clínica Durval Marcondes.

\section{Sobre a transferência na psicose}

Foi na leitura da obra de Lacan guiada pela leitura dos comentadores da École Lacaniènne de Psychanalyse que pude encontrar subsídios teóricos para me orientar na difícil tarefa que essa clínica representa.

Em nosso meio é hegemônica a teorização que afirma, a partir da leitura do texto lacaniano, a inexistência de transferência na psicose. A ferida produzida pela forclusão do Nome-do-Pai deixaria sem entrada o caminho de acesso pela via da psicanálise. Não ha- 
veria a suposição de saber feita sobre a figura do analista e, assim, as portas estariam fechadas. Essa teoria acrescenta à concepção de transferência feita por Freud a questão do saber, acréscimo lacaniano sem dúvida, mas segue a teoria de Freud no que tange à concepção do processo de subjetivação, que em Freud passa pelo Édipo, e que é dito lacanianamente, da forma como Lacan se expressa no seminário "As psicoses", ao analisar o caso Schreber, como forclusão do Nome-do-Pai.

Supor a existência de uma transferência na psicose requer outra leitura dessa mesma teoria, e certa ousadia, ao propor que essa via de subjetivação proposta por Freud, e adotada na leitura mais corrente sobre o assunto, que vai do autoerotismo à relação de objeto, que essa via não é a única possibilidade de subjetivação humana. O que significaria propor, por exemplo, que a loucura é uma forma de subjetivação humana, da mesma forma, aliás, que o próprio Lacan (1998a) sugere no caso da neurose, para o sintoma, no texto Instância da letra no inconsciente:

E também para levar a compreender que na coextensividade do desenvolvimento do sintoma e de sua resolução curativa revela-se a natureza da neurose: fóbica, histérica ou obsessiva, a neurose é uma questão que o ser coloca para o sujeito "lá onde ele estava antes que o sujeito viesse ao mundo" (essa subordinada é a própria frase de que se serve Freud ao explicar o complexo de Édipo ao Pequeno Hans).

Trata-se aqui daquele ser que só aparece no lampejo de um instante no vazio do verbo ser, e eu disse que ele formula sua questão ao sujeito. Que significa isso? Ele não a coloca diante do sujeito, pois o sujeito não pode vir para o lugar onde ele a coloca, mas coloca-a no lugar do sujeito, ou seja, nesse lugar, ele coloca a questão com o sujeito, tal como se enuncia um problema com uma caneta e como o homem de Aristóteles pensava com sua alma. (p. 524)

O sintoma neurótico é concebido aí, portanto, como uma via de subjetivação pelo que se lê acima. É importante fazer aqui um desdobramento. O que falha na psicose é a constituição de um eu, e isto é sem dúvida um problema, mas em Lacan fala-se em sujeito, e esse conceito não coincide com o eu. $\mathrm{O}$ sujeito não é o eu. O sujeito está ligado ao desejo de $a$.

E o que Allouch afirma, lendo Lacan, é que a loucura e suas manifestações podem ser concebidas também como forma de subjetivação. Que a loucura é humana, assim como a neurose o é. Que a loucura é literante. 
Para falar da transferência nesta clínica colocarei meu texto em interlocução com Léthier (Brauer, 2010), quando ele afirma que a loucura é um processo que envolve várias pessoas, e com Allouch (1986 e 1994) e sua afirmação de que existe sim uma transferência na psicose, e que ela acontece do lado do analista. Vou tentar, entremeada nesses discursos, trazer a contribuição de minha investigação clínica desenvolvida nesse campo, apoiada desde 1997 na leitura desses autores e na interlocução com eles, guiada, principalmente, pela forma como eles efetuam o estabelecimento e a leitura do texto lacaniano no seminário da Angústia (n.d.). Tento aqui uma teorização daquilo que aprendi em meu trabalho.

Parto então do pressuposto de que existe sim uma transferência nessa clínica dos distúrbios graves na infância, o que nos permite a nós, psicanalistas, uma aproximação e o desenvolvimento de um trabalho de análise. E, como se trata de ideias que são pouco difundidas no nosso meio, é importante que eu dedique um espaço à sua exposição, o que farei a seguir.

$O$ ponto intrigante em torno do qual minha pesquisa vem se desenvolvendo é o de que é necessário, quando se quer desenvolver um trabalho de análise com uma criança que apresenta distúrbios graves - um autista, um deficiente, um psicótico -, ampliar a visada e adotar um recorte da situação clínica de tal forma que o trabalho englobe a criança que nos é trazida como cliente e também aquela pessoa que se dedica ao seu cuidado: seu pai ou sua mãe, ou talvez um irmão mais velho, a avó; enfim, de que é frutífero trabalhar com um enfoque não individual, prestar atenção aos desdobramentos que ocorrem na cena familiar, uma vez que nos propomos a avançar nessa clínica. Essa é a constatação e ao mesmo tempo a questão que tem movimentado minha investigação nos últimos anos.

Como falar de transferência nesse contexto? Ou será que justamente esse contexto transferencial poderia contribuir para a compreensão do conceito de transferência? Essa última é justamente a minha aposta, apoiada no texto de Allouch, que faz essa aposta também, e que eu resumirei a seguir.

\section{O que haveria de específico na transferência quando se trata de um psicótico?}

Allouch (1986), no texto Vous êtes au courant, il y a un transfert psychotique, indicado acima, diz que a transferência na psicose é a transferência do analista:

A loucura demanda por ajuda. Esta fórmula tem múltiplas ressonâncias; trata-se de uma demanda aos pequenos outros, mas também da demanda à transferência que ela provoca [itálico nossos]. Ela só tem esta pregnância, só age como 
esta força aspirante, que não tem nada a invejar ao fantasma, pelo fato de ter um modo de enunciação específico e ordenado segundo três lugares que propomos distinguir.

O lugar daquele ou daquela que dizemos psicótico é fundamentalmente aquele de uma testemunha (temoin). Escrevamos mesmo tu és menos (t'es moins) para ouvir isso que sua postura sempre comporta: a ferida narcísica.

O lugar do Outro é aquele de onde se origina uma atribuição dessubjetivante, persecutória em si mesma. Afirmação feita de forma tão absoluta que exclui a possibilidade de que o sujeito possa fazer sua demanda a partir deste lugar, que possa fazer reconhecer aí a validade de seu testemunho. Isto quer dizer que nós nos proibimos nas análises de psicóticos, sistematicamente, toda interpretação, no sentido do jogo sobre o equívoco significante.

O lugar do outro - escrito com letra minúscula - é aquele onde o sujeito faz valer seu testemunho. O pedido é formulado aí como a uma instância que seria o Outro do Outro, e que, portanto não existe, só podendo então se assentar como pequeno outro. Isto faz com que não reste então alternativa entre recusar a testemunha ou co-delirar com ela. ...

É aqui que brilha a especificidade da transferência psicótica que é antes de tudo, Lacan o notou, uma transferência ao psicótico [itálico nossos]. Ela se define em relação ao saber e tendo mesmo razão em seu saber. E nós não obteremos nada dele se lhe recusarmos isso. E por uma razão de estrutura...

O psicótico tem, Lacan o formulou, seu objeto a no bolso. É ele, portanto, que, na disparidade subjetiva de nossa relação a ele, é o eromenos, enquanto nos retorna a função de erastes.

Só engajamos a análise com um sujeito psicótico por não excluirmos a priori que possa se produzir nela esta báscula pela qual o eromenos se transforme em erastes. (pp. 100-101)

É assim que Allouch enuncia que, no momento em que se engaja uma análise de um psicótico, a transferência tem essa especificidade de ser uma transferência ao psicótico. E, observação muito importante, afirma também que só engajamos a análise com um sujeito psicótico contanto que possa se produzir nela essa báscula pela qual o eromenos se transforme em erastes.

Considero que seja de grande importância frisar esse ponto. Esperançoso por um lado, por afirmar a possibilidade de uma análise, ele nos adverte que para desenvolver essa clínica há que se percorrer um (longo) caminho que requer de nós, analistas, uma intervenção delicada sobre esse amor de transferência, no caso o nosso próprio, intervenção esta que nos recoloque no lugar de amado que nos convém. Conforme as observações de Lacan (1956):

fazendo referir a transferência ao desejo do analista Lacan pôs fim à situação sem rigor e sem lógica da transferência na análise ... fazendo entretanto 
valer aí, com o neurótico, um modo de inscrição do psicanalista na transferência que tem sua pertinência primeira ao nível das psicoses. Lacan não 'força a barra', mas reconhece o fato de que, em todos os casos, a análise instaura a subjetividade da única forma que é possível: na destituição subjetiva. (p. 101)

Trata-se, pois, de uma posição em um jogo. O seu ponto de partida, e que deverá ser depois revertido para possibilitar a intervenção. É o que indica a leitura deste texto.

Isso está ligado ao fato de que, conforme Allouch o afirma, o louco demanda por ajuda. Ligado, portanto, à forma como o psicótico demanda amor, essa forma intensa que toma o analista levando-o a transferenciar-se ao louco, e a inadvertidamente se propor a ajudá-lo, no real muitas vezes, o que o tira de seu lugar. A leitura do caso Aimée aponta para isso, mas o trabalho com o louco o reafirma no dia a dia. Isso é fato de estrutura, afirma Allouch.

Em minha experiência, no caso das crianças, encontrei alguns dos elementos apontados por Allouch. A questão ligada ao testemunho me levou em 1987 a propor uma abertura, uma ousadia, e receber as mães das crianças que eu acompanhava no IP-USP. Ceder àquilo que era insistentemente demandado. $\mathrm{O}$ que se descortinou daí foi a possibilidade do exercício desse testemunho de que fala o autor. Nessa clínica, no entanto o que se constata é que a transferência se coloca do lado da mãe, e em relação 
à criança. Dito mais diretamente, a mãe tem uma transferência com sua criança, cujo distúrbio constitui um posicionamento, a posição que bem pode ser pensada como um testemunho de algo que será tratado depois com essa mãe. A criança é o pivô, a evidência deste testemunho.

Quanto à criança, ela põe algo em cena, mas não nos demanda nada. É a mãe quem demanda. Esse desdobramento, próprio de determinados casos, permite concordar com as afirmações de Allouch, e também colocar nossas indagações nesse ponto que suas teorizações propiciam.

Ante o embaraço dessa transferência que nos coloca justamente ali onde não devemos estar, como fazer?

Em minha experiência ousei jogar o jogo, "testemunhar" a cena que se apresentava no aqui e agora clínico, essa irrealidade louca. Verifiquei depois que ela se reportava à história dessas pessoas, da mãe, da criança e procurei produzir um deslocamento que permitisse ao analista ocupar o lugar de testemunha, portanto esse lugar indesejável e incômodo. A filigrana que essa postura permitiu foi seguir um significante deslizando, do comportamento da criança, de sua forma de agir, portanto, ao discurso da mãe ao relatar sua história. Trabalhamos, portanto, na posição indesejável de erastes, o que não deixou de produzir seus efeitos. Um deles, estimulante, foi a melhora das crianças, sua saída desse estado de congelamento autista, e a saída da criança, e sua conse- quente melhora, permitiu a báscula, o reposicionamento do analista para o lugar que lhe convém e, com isso, o início da análise da mãe no caso. $\mathrm{O}$ outro foi o envolvimento da equipe que eu coordenava, que eu diria que estava identificada com essa posição de erastes, demandando por ajuda no lugar das mães.

O que fazer com isso? A pergunta permanece e procuramos na teoria alguma reposta que possa nos orientar.

Allouch sustenta que Freud e Lacan têm pontos de partida diversos em seus percursos.. Freud (1985) parte, em sua teorização, da clínica da neurose, da clínica da histeria:

Começamos a compreender - de forma melhor talvez na América - que somente o estudo psicanalítico das neuroses pode oferecer uma preparação para uma compreensão das psicoses, e que por esse motivo a psicanálise é chamada a tornar possível uma psiquiatria científica no futuro. (p. 91)

Partindo do conceito de narcisismo, Freud aborda a neurose e supõe que o mesmo conceito permitirá a abordagem das psicoses. Allouch (1994), no entanto, afirma que abordar as psicoses tendo como ponto de partida as neuroses seria:

operar, em seu seio, uma discriminação, uma triagem, devendo umas ser reelaboradas, o que significa ser invalidadas, enquanto que as outras poderiam ser chamadas, neste novo terreno, a dar toda a medida do seu valor heurístico... 
pode-se dizer que esta maneira de pensar tenha sido efetuada de sorte que, desde os primeiros passos, a abordagem psicanalítica das psicoses se tenha feito de forma largamente hipotecada, detivemo-nos aí, para o essencial, à hipoteca neurótica, ao menos lá onde se oficializa a doutrina. (pp. 507-508)

Não é difícil concordar com essa tese de Allouch, ou mesmo se deixar levar por ela.

No caso de minha pesquisa, desenvolvida no IP-USP, quando decidi iniciar aí a oferta de um atendimento analítico a determinados pacientes que nos procuravam, foi necessário sustentar e, mesmo defender, a ideia de que esse atendimento seria possível, lutar por isso. Minha iniciativa provocou a instituição na sua própria estrutura. Fundada por Durval Marcondes nossa clínica foi constituída a partir das ideias de Freud e nos mesmos moldes da Sociedade Brasileira de Psicanálise, que ele também fundou. Historicamente atendiam-se aí pacientes neuróticos, os psicóticos eram triados e encaminhados para outras instituições. $\mathrm{Na}$ época em que foi constituída a clínica que hoje leva o nome de seu fundador não se conhecia ainda em nosso meio o texto de Lacan.

E, no entanto, eu sabia, de um saber extraído exclusivamente de minha experiência clínica, que transferência havia, ainda que segundo um desenho muito peculiar, o qual justamente eu tinha a intenção de pesquisar. Ou seria melhor dizer que eu vislumbrava a possibilidade do estabelecimento de um vínculo com a criança dita incapaz de vínculo? Era preciso verificar.

Nossa clínica-escola fora constituída a partir do texto freudiano, e, mesmo que em 1987 (quando iniciei meu trabalho de investigação) já se desenvolvesse em nosso meio a leitura de Lacan, este autor era tido, como ainda o é nos dias de hoje, na forma como aliás o próprio Lacan se referia a si mesmo, como freudiano, leitor, seguidor de Freud.

Allouch, no entanto, sustenta nesses dois textos que estou apresentando aqui que Lacan, partindo do caso Aimée, uma paranoica, acabou por desenvolver uma teoria diferente da de Freud, em interlocução com a teoria freudiana, evidentemente, mas diferente dela. Uma teoria que lhe permitiu afirmar, diferentemente do que Freud propôs, que existe sim uma transferência na psicose. Sigamos Allouch (1994) e sua argumentação, pois ela sublinha aquilo que haveria de exclusivamente lacaniano no texto de Lacan em decorrência de seu percurso:

602 Estilos clin., São Paulo, v. 18, n. 3, set./dez. 2013, 591-612. 
Pode-se crer que o caminho aberto por Lacan, neste momento inicial que estudamos aqui, se situa nesta perspectiva oferecida por Freud a uma psiquiatria nova, científica, cujo ponto de partida é a psicanálise (ele foi aberto pela ruptura da ligação Freud/Fliess, e sabe-se que C. G. Jung foi convocado a se distinguir neste campo). Nossa leitura da tese de Lacan demonstra que este não foi o caso; Lacan não reconduziu a hipoteca neurótica e podemos apostar, aliás, que foi este mesmo afastamento que incitou Freud a querer fazer de Jung seu herdeiro em um sentido sem dúvida preciso uma vez que Jung era convocado a ser nada menos que o Freud da psicose. Não se pode dizer que Lacan neste ponto prolonga Freud. Acrescentemos: felizmente. Pois existe em Freud, no que concerne o problema da transferência psicótica, alguma coisa como um ponto de partida falso - através do qual é inútil continuar a correr! Lacan, dito de outra forma, não faz imediatamente seus um certo número de dados adquiridos a partir das neuroses e supostos como facilitadores da abordagem das psicoses. O caminho que ele abre cruza o de Freud; ele não cai em heresia, pois ele não começou assimilando o passo de Freud. Vamos dar alguns indícios desta recusa de um certo número de presunções, em Lacan.

Todo ser humano deveria percorrer um caminho, quase que preestabelecido, que, do autoerotismo, o conduziria à felicidade da relação de objeto. Está aí uma das bases doutrinais da ideia segundo a qual não existe transferência nas psicoses. Tal aquisição faz parte do núcleo da psicanálise? A análise está condenada a desaparecer se parar de afirmar o primado, a um só tempo histórico e estrutural, do "auto" sobre o "hétero"? O que se seguiu demonstrou que ter substituído um narcisismo primário ao autoerotismo primeiro não permitiu retificar o falso ponto de partida. Um dos maiores indícios que nos permite adiantar isso consiste na sua recusa (de Lacan) em admitir o autoerotismo como primeiro. Daí, nele, esta outra definição: o autoerotismo tem a ver com "a desordem dos pequenos a", é "quando se falta de si". Não existe, portanto nada de "auto", senão a designar, dialeticamente, e não mais mecanicamente, aquilo que existe quando não existe o "auto".

Da mesma forma o delírio. Longe de ser um dado solipsista, longe de denotar sabe-se lá qual pregnância de um narcisismo dito primário, o delírio irá marcar, em Lacan, aquilo através de que um sujeito entra em pleno voo no domínio da intersubjetividade ${ }^{3}$.

Assim se vê a exemplaridade do fenômeno delirante retornar em Freud ao delírio de grandeza ao passo que ele se situa no delírio de perseguição com Lacan.

Da mesma forma o problema da "perda de realidade" ou aquele, correlativo, da "despersonalização" encontram-se postos de forma completamente diferente na tradição psicanalítica ortodoxa e em Lacan. Assim nos Complexos familiares: o acesso à realidade e, em paralelo, a constituição da personalidade como acabada dependem de um processo; as psicoses sobrevêm então não mais deficitariamente, mas como uma parada em um processo que muda de direção. Não existe a perda, mas a não constituição da realidade, não há despersonalização, mas não personalização (donde o achado clínico da hipernormalidade de certas personalidades antes que elas sejam confrontadas à situação potencialmente desencadeante da psicose). 
... Pelo contrário, coube a Lacan ter proposto a figura do SsS como ordenadora da transferência, como sendo sua "formação, não de artifício mas a sua veia". Desde então surge uma suspeita, rapidamente transformada em interrogação: não seria por ter partido de um questionamento das psicoses que o caminho aberto por Lacan chegou a distinguir essa figura do SsS, a lhe dar sua função de pivô da transferência? (pp. 509-510).

Essa é justamente a tese que Allouch defende aqui. De que Lacan não é freudiano quando aborda as psicoses, e de que isso tem consequências importantes em sua teorização e sem dúvida sobre a forma como lemos seu texto: "A transferência psicótica colocada inicialmente por Freud como inexistente passa a ser recebida, com Lacan, como caso exemplar de toda transferência”. (pp. 510-511).

Essa questão, que pode ter a aparência de uma simples querela, de um preciosismo lacaniano, é digna de nota por suas consequências. Considerar a transferência psicótica como, em primeiro lugar, existente e, em segundo lugar, como caso exemplar de toda a transferência modifica a clínica do psicanalista, possibilitando o atendimento de uma série de casos que de outra forma estariam excluídos do campo da psicanálise e dos eventuais benefícios que uma análise possa trazer. Em meu trabalho pude constatar que esses benefícios existem, e que não são de pequena monta.

As ideias de Allouch são ousadas, ele propõe que o caminho que vai do autoerotismo à relação de objeto não é um caminho de subjetivação necessário, universal. Ou seja, que há outros caminhos possíveis. Ele ultrapassa com isso toda a teoria sobre a psicose baseada exclusivamente na ideia de forclusão do Nome-do-Pai. O que Allouch está propondo é que a psicose teria um caminho de subjetivação em alternativa à forma neurótica de subjetivação. Que o delírio em Lacan é a forma como o sujeito entra no domínio da intersubjetividade. Que a psicose é uma parada em um processo que muda de direção e no qual a realidade não chegou a se constituir.

São formas de dizer que abrem uma perspectiva que irá desembocar nas ideias que Lethier sustenta: no abandono de uma visão reabilitadora na clínica das psicoses (já que não se constitui em um defeito, mas em outra forma de subjetivação), na psicose como passagem que produz um traço, numa subjetividade não necessariamente pessoal (já que, não tendo construído a realidade, o psicótico não separa o $e u$ do $t u$, englobando o outro na sua subjetividade, um outro que não adveio outro).

Falando sobre o matema da transferência (SsS), Allouch fará um importante desdobramento. Ele separa a transferência e o SsS ou, ainda, ele explica a transferência, esse fenômeno que fica situado entre um sujeito que ainda não é, e um Outro que é tomado como sendo esse sujeito, e que supostamente sabe. Para isso ele nos guia reconstruindo o caminho percorrido por Lacan em seu seminário 
para forjar esse matema. A leitura do próprio texto de Allouch é mais do que recomendada. Limito-me aqui a resumi-lo.

Primeiro ponto, a contraposição entre o saber e a possibilidade de engano, o problema da discordância com a realidade.

Percorrendo os meandros da interlocução de Lacan com o cogito cartesiano, interlocução esta que deu origem à ideia de um sujeito suposto saber segundo Lacan, Allouch (1994) lembra: "O suposto saber não é, portanto, atribuível a um Outro e sim a um sujeito.” (p. 515).

Situando a argumentação no debate de ideias que Lacan, fundador de uma nova episteme, estabelece com o texto cartesiano e seus paradoxos e também que essa leitura lacaniana de Descartes se produz sobre o fundo de um questionamento das psicoses, em seu campo paranoico, onde a regra é: não que o sujeito se tome por, mas que seja tomado por, e no lugar do Outro. Em que o saber é inicialmente aquele que está no lugar do Outro, isso, como eu dizia, no campo da paranoia. Abre-se aí uma questão que será equacionada pela seguinte afirmação de Lacan (1968): “Um sujeito não supõe nada, ele é suposto. Suposto, nós ensinamos, pelo significante que o representa para um outro significante” (n. d.).

Essa afirmação procede à escritura do matema da transferência, que se

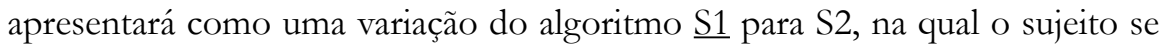
encontra subposto (sous-posé) pelo significante da transferência e o saber (os significantes inconscientes) posto em contiguidade com esse sujeito subposto. Trata-se de um significante não subjetivado, esclarece Allouch (1994), do único significante não subjetivado. $\mathrm{O}$ sujeito, nesse caso fica entre o analisante e $\mathrm{o}$ analista, na transferência:

Os significantes no inconsciente são, eles também, assim denominados por antecipação, e pela mesma razão. É isso que escreve o parêntesis. Eles não estão, entretanto, no mesmo nível que o significante da transferência. Sublinhamos assim que o significante da transferência não está posicionado como um significante no inconsciente. Se esses significantes não advêm como tal a não ser pelo acontecimento de uma e depois mais uma ... interpretação, e se, como foi notado várias vezes, a interpretação supõe a transferência, podemos mesmo chegar a dizer que o significante da transferência abre a possibilidade da interpretação, e portanto da produção de S1, S2, etc. Evocou-se várias vezes o paradoxo próprio à dita "interpretação da transferência": nascida do fato que ela se funda na transferência, como ela poderia reabsorvê-la? A disparidade de posição, escrita no matema da transferência, entre os significantes no inconsciente e o significante da transferência deixa entrever que este paradoxo não é um paradoxo.

Notemos enfim o equívoco do s, equívoco que é aquilo que resta da exclusão do Outro suposto saber. O pequeno s transcreve o sujeito na fórmula sujeito suposto saber. Enquanto subposto (sous-posé) por um significante $\mathrm{S}$, este sujeito seria um sujeito barrado desde que esse $S$ viesse representá-lo para um outro significante, para o significante qualquer. Mas este não é o caso, e Lacan faz ato disso escrevendo esse sujeito com um s minúsculo e não como em outros matemas (por exemplo aquele dos quatro discursos), S maiúsculo barrado:\$. S 
minúsculo é um sujeito que carrega um saber não sabido (entre parêntesis). Mas ele é também o sujeito em espera de ser representado por um outro significante para um outro significante. Seria preciso então poder escrever, em um espaço tridimensional, S barrado em um segundo plano em relação a esse pequeno s. Entretanto esse problema não é espacial, mas temporal, e essa temporalidade se apresenta como sendo a razão pela qual não se trata de contar aqui, a despeito do equívoco que nós assinalamos, dois sujeitos (em sua Proposição, Lacan não só recusa a intersubjetividade mas, mais que isso, faz ato de que: "a transferência faz por si só objeção" à intersubjetividade). Trata-se de dois tempos diferentes do sujeito, de um modo de subjetividade que reconhece no acontecimento denominado transferência seu caráter possivelmente transitório.

Nós afirmamos que o matema da transferência permite demarcar ao mesmo tempo a unidade de seu conceito e a diversidade clinicamente sensível de suas realizações especialmente nas neuroses e nas psicoses. (pp. 517-518)

Muito importante o desdobramento feito pelo autor, destacando o sujeito na transferência, que é suposto na figura do analista. Leitura que é evidentemente possibilitada pelo próprio matema ( $\mathrm{Ss} S)$.

$\mathrm{E}$ assim, nesse equívoco que ocorre sempre na transferência, Allouch afirma que na psicose o equívoco implica de saída que a transferência esteja do lado do analista, e em função do fato de que o louco sabe, ele não supõe o saber no Outro. Ele sabe e faz um testemunho disso ao analista.

E, retornando ao ponto de onde partimos, Allouch afirma logo de saída que a loucura demanda por ajuda. Então podemos contar com a demanda nessa clínica, uma demanda maciça, que nos coloca em movimento. Uma demanda que, longe de ser uma solução, é ela mesma um problema. Mas não seriam exatamente esses embaraços, esses equívocos, que constituem a cena de toda análise?

Nessa mesma perspectiva, Allouch afirma que a loucura efetua o significante em ato, a loucura é ela também um caminho possível para que o sujeito escreva sua questão.

\section{Ponto de ato}

Foi justamente esse ponto de ato que constituiu para mim a porta de entrada que me deu acesso ao complexo desenvolvimento teórico realizado pelo mesmo autor e, antes disso, ao complexo emaranhado que era apresentado no atendimento aos pacientes aos quais eu me dedicava. Essa dimensão de ato marcava sua presença nos 
atendimentos que eu supervisionava no IP-USP, em todos eles.

A cena clínica, se não obedecia nem de longe ao formato tradicional em que o paciente está deitado no divã e o analista instalado em sua poltrona, parecia-se mais a uma dança ritual, na qual mãe e criança faziam seus movimentos obedecendo a alguma coreografia, sempre enigmática para nós. Tratava-se, naquele então. de encontrar um espaço possível para nos inserirmos nessa dança carregada de erotismo, um erotismo não genital, evidentemente, um erotismo no sentido que Freud deu a esse termo um dia. O que procurávamos? Um lugar na transferência?

É preciso ser franca e dizer aqui que essa questão de transferência não me ocupou conceitualmente muito na maior parte do tempo em que desenvolvi meu trabalho com esses pacientes. De fato, aquilo que pesquisei na teoria e na clínica foi uma forma de tratar o ato. Eu a encontrei. Tratavase, clinicamente falando, de ler, ou dar a ler aquilo que acontecia em ato. Ler a partir da história dessas pessoas aquela lacuna que o ato realizava, para poder dizer mais tarde, guiada pelos textos escritos pelos colegas da École Lacaniènne, nessa forma precisa de dizer, de efetuação do significante.

Respeitar a criança em seu agir, e mais, buscar a leitura desse mesmo agir no relato que a mãe fazia da história familiar e da história da criança, isso mudava toda a cena. Aquela criança que nos havia chegado muito 
mal agora já passava a falar, a brincar, e rapidamente encontrava uma forma de sair do tratamento e de se engajar na vida corrente de uma criança, à qual ela não tinha acesso até então, ou na qual encontrava entraves e dificuldades, antes do tratamento. Algumas crianças deitavam-se no divã e faziam análise. As mães entravam em análise e diziam então que finalmente eram ouvidas. Era no real que se efetuava, portanto, o significante, construindo cenas, criando cenas.

No conto $A$ terceira margem do Rio de João Guimarães Rosa (2008), o narrador fala da decisão de seu pai, que, em um dado momento, decidiu dar

um adeus para a gente... Nosso pai não voltou. Ele não tinha ido a nenhuma parte. Só executava a invenção de se permanecer naqueles espaços do rio, de meio a meio, sempre dentro da canoa, para dela não saltar, nunca mais. A estranheza dessa verdade deu para estarrecer de todo a gente. Aquilo que não havia, acontecia... todos pensaram de nosso pai a razão em que não queriam falar: doideira. (p. 37).

E aí está Guimarães Rosa a nomear tão bem aquilo de que se trata no acontecimento da loucura: "Aquilo que não havia, acontecia".

Minha proposta, no trabalho analítico com a psicose, foi, posso dizê-lo agora que estou amparada pela palavra de Guimarães Rosa, acompanhar esse "acontecer", deixar que ele se efetuasse, propiciando que se escrevesse o significante que havia ficado a meio caminho. Permitir com isso sua leitura.

Voltando ao belo conto de Rosa, apreciemos o modo como o autor faz essa passagem que permite ao sujeito se inscrever entre dois significantes ${ }^{4}$. Guimarães Rosa efetua o sujeito, através dessa construção de frase em que ele acrescenta à regência do verbo permanecer um se. Ilustra dessa forma o proposto por Guy le Gauffay (2009), no seu C'est à quel sujet? Fazendo recurso a uma análise que lhe permite falar do sujeito lacaniano, Gauffay diz:

Frequentemente, esse acréscimo de um agente ${ }^{5}$ apenas desdobra o sujeito de uma forma que poderíamos crer, em uma primeira abordagem, reflexiva. Assim, na forma de falar do Sul da França, podem-se ouvir todos os dias frases como: "Je me la mangerais bien cette petite côte de porc". Dir-se-á tratar-se de um hispanismo, já que em espanhol essas formas são regulares. Verdade, mas essa explicação geográfica falha, entretanto, ao não considerar o problema enunciativo que faz com que je me la mangerais bien não seja apenas um regionalismo, mas um enunciado muito diferente de je la mangerais bien.

608 Estilos clin., São Paulo, v. 18, n. 3, set./dez. 2013, 591-612. 
Comer alguma coisa e se comer alguma coisa são semanticamente dessemelhantes, e se ocorre ao linguista articular sua diferença, ocorre ao analista perceber aí um posicionamento subjetivo diferente, que não se reduz em nada à forma reflexiva. Pois o sujeito não se come, ele mesmo: ele se come alguma coisa. Ele acrescentou um agente, sem para tanto se tomar como o objeto do verbo, como quereria a voz reflexiva.

Por essa repetição pronominal, esse sujeito se constitui ao menos como o endereço do ato que ele engaja. Se nossa língua declinasse - quero dizer: desenvolvesse declinações - seria um dativo que seria chamado ao seu lugar. Suplementando o verbo com um agente que não é outra coisa que ele sob um outro modo gramatical, o sujeito torna complexa sua posição fazendo-se de alguma forma de paciente do seu ato. (p. 39)

Dizendo se permanecer Guimarães Rosa faz então, como cogita Le Gauffay, com seu "Je me la mangerais bien" o acréscimo de um agente, faz de si mesmo o paciente do ato que engajou. Assim o diz o filho que narra o ato do pai no conto de Guimarães Rosa, que escreve o conto.

\section{Muito complicado isso!}

Mas como escrever essa letra que se efetua nessa clínica?

Há um fato que testemunhei muitas vezes como orientadora de teses e dissertações no programa de pós-graduação do IP-USP. Tratase da possibilidade de acontecer que um colega que vem trabalhando em instituições como os Centros de Assistência Psicossocial (CAPS) procure a pós-graduação para escrever sobre um caso que atendeu, ou que está atendendo. Tenho entendido que esse movimento acontece a serviço da própria clínica e tenho aceitado orientar esse tipo de pesquisa. Proponho aqui que o profissional, fazendo assim, efetue um movimento que completa aquele que foi iniciado no ato do paciente. É a voz, ou o texto do profissional que vai pôr na letra, escrever, aquilo que comparece como ato do lado de seu paciente.

Então, pode-se supor um sujeito na psicose, e também uma transferência. Mas está em jogo uma subjetividade que neste caso "não é necessariamente pessoal", como afirma Roland Lethier. Uma subjetividade que precisa se apoiar nessa relação entre essas pessoas para poder advir. E então já não se trata de saber o que é de quem, mas, como disse Guy le Gauffay (2010), de saudar o sujeito que aparece nesse clarão de um instante no vazio do verbo ser. 
Mas como exercer essa clínica assim tão complexa que se apoia numa modalidade de transferência em que o analista irá, sem se dar conta disso, sem pretender realizar isso, fazer um com seu analisante para assim emprestar uma materialidade ao objeto $a$ ?

Entendo que aquilo de que se trata é de acolher o movimento que se instala nessa transferência e que toma o analista como parte dele. E o analista o faz oferecendo para isso os espaços de que ele dispõe.

Mas é preciso voltar ainda um instante. Vista dessa perspectiva a loucura passa a ser considerada uma forma de criação humana, bem ao contrário do que diz a palavra doideira que Guimarães Rosa emprega no conto que acabo de citar, reproduzindo, é claro, o dizer do brasileiro a esse respeito.

Ao consultarmos o Dicionário etimológico da língua portuguesa de Antonio Geraldo da Cunha (1986), veremos que loucura é uma palavra de etimologia desconhecida. O dicionário nos remete a doido, doudo, e é então que encontramos o seguinte: douda é uma doença que dá no gado. Dizer doideira sugere, portanto, que se trata de uma doença do bicho homem, algo de seu corpo, que não se trata de algo humano no acontecimento da loucura, no sentido de humano como ser de cultura, como ser de linguagem. Eis a forma como essa concepção da loucura, veiculada na medicina, já se encontra antes disso enraizada na linguagem popular mesma, na língua portuguesa. E eu me pergunto, o que teria vindo antes? Seria a visão popular da coisa, o preconceito, ou o conceito?

Mas não vamos romancear as coisas. É verdade que o próprio Lacan afirma, lê em Freud, que o homem é poeta em seu sintoma, sim, e que, concebendo a loucura dessa forma, como uma mise en scène, como uma poética, seguimos na mesma direção.

Longe de ver na arte uma forma de terapêutica da loucura, o que vou concluindo é que esse termo pulsão, forjado no campo da psicanálise, diz de algo que nos impulsiona a realizar, a criar, e que como tudo tem ao menos dois lados, podemos ver num extremo desse contínuo a arte, a poesia, e, no outro, a loucura, como formas de realização desse impulso, digamos, dentro de estéticas diversas. A loucura, e também a neurose, esse extremo em que o material a ser forjado é a própria carne.

Pensando dessa forma eu entendi, ao escrever meu projeto em 2002, que poderia ser interessante munir nossos pacientes de linguagens diversas, apresentar a essas crianças que se encontravam 
completamente à margem da cultura, no sentido amplo, várias linguagens que nela circulam. Assim, poder comer juntamente com um grupo de pessoas, poder brincar, desenhar, participar da realização de um filme ou da escritura de uma partitura musical, ler, escrever... é um fato que essas coisas eram novas para nossos pacientes, um fato assombroso.

Os efeitos disso traduziram-se na possibilidade de criação de laços afetivos, e da formação de um grupo. Vários pacientes conseguiram se incluir na escola.

Até onde pude caminhar nessa clínica posso afirmar hoje que é possível sim submeter a loucura a um trabalho de análise, e que isso contribui positivamente na vida dessas pessoas que sofrem com a loucura, sejam elas o louco ele mesmo ou as pessoas que com ele convivem. É válido incluí-las clinicamente nesse campo da psicanálise, sem pretender no entanto através dela uma cura da loucura, ou do autismo. Pois não é com a patologia que lidamos, mas com o erotismo.

\section{TO CONCLUDE A RESEARCH PROJECT}

\section{Abstract}

The article reflects on the activities developed in a Project of research accomplished in Universidade São Paulo between years 2002 and 2007, focusing the transference modality that developed on the clinic with children diagnosed as autists and the related difficulties, having as an goal to theorize in the field of the psychoanalysis.

Index terms: psychoanalysis; autism; transference; psychoanalitical clinic.
PARA CONCLUIR UN PROYECTO DE PESQUISA

\section{REsúmen}

El articulo piensa en las actividades que se desenvolveran en un proyecto de pesquisa realizado en la Universidade São Paulo entre los años de 2002 e 2007, destacando la transferencia que se desenvolvió en la clinica con niños diagnosticados como autistas e las dificultades que resultaran, teniendo como objetivo teorizar en el campo del psicoanalisis.

Palabras clave: psicoanalisis; autismo; transferencia; clínica psicoanalitica.

\section{REFERÊNCIAS}

Allouch, J. (1994). Du transfert Psychotique. In Margueritte, ou L'Aimée de Lacan (2a ed.). Paris: EPEL.

Allouch, J. (1986). Vous êtes au courant, il y a um transfert psychotique. In Littoral, 21. (Identité psychotique), 89 a 112.

Brauer, J. F. (1988). O teste das pirâmides coloridas de Max Pfister - uma re-leitura. Tese de doutorado, Instituto de Psicologia, Universidade de São Paulo.

Brauer, J. F. (2000). A criança no discurso do Outro - Ensaios sobre a clínica dos distúrbios graves na Infância. Tese de Livre-docência, Instituto de Psicologia, Universidade de São Paulo.

Brauer, J. F. (Org.) (2010). Seminários Brasileiros de Roland Lethier. Recuperado de http:// newpsi.bvs-psi.org.br/ebooks2010/es/ Acervo_files/Seminarios-BrasileirosRoland.pdf.

Cunha, A. G. (1986). Dicionário etimológico da lingua portuguesa ( $2^{\mathrm{a}}$ ed.). Rio de Janeiro: Lexikon Editora Digital.

Freud, S. (1985). Petit abrégé de psychanalyse. In Résultats, idées, problèmes (tomo II, p. 112). Paris: PUF.

Rosa, J. G. (2008). A terceira margem do rio. In Primeiras histórias (p. 37). Rio de Janeiro: Media fashion.

Lacan, J. (1956). Le séminaire livre III. Lespsychoses, 1955-1956. Paris: Le Seuil. 
Lacan, J. (1968). Proposition du 9 octobre 1967 sur lê psychanalyste de l'École Scilicet 1. Paris: Seuil.

Lacan, J. (1985). Le symptôme; conferência feita no Centre F. de Saussure em Genebra. In Bloc-notes de la psychanalyse, 5, 5-23.

Lacan, J. (1998a). A instância da letra no inconsciente ou a razão desde Freud. In Escritos. Rio de Janeiro: Jorge Zahar Editor.

Lacan, J. (1998b). Escritos. Rio de Janeiro: Jorge Zahar Editor.

Lacan, J. (n.d.). L'angoisse (transcrição realizada por Roussan - inédita).

Le Gauffay, G. (2009). C'est à quel sujet (p. 39). Paris: EPEL. (tradução livre)

Le Gauffay, G. (2010). Lacan per via de levare. Buenos Aires, seminário de agosto.

Perec, G. (2009). A vida modo de usar. São Paulo: Companhia de Bolso.

\section{Notas}

1. Conforme se pode ler em Lacan, J. Le symptôme, conferência feita no Centre F. de Saussure em Genebra no dia 4 de outubro de 1975 em uma jornada organizada pela Societé Suisse de Psychanalyse e publicada no Le Bloc - notes de la Psychanalyse, 1985, n. 5, pp. 5 a 23.
2. Termo criado por Freud para denominar o ponto que o intrigava na esquizofrenia, o autoerotismo fará seu caminho na psicanálise, mas também originará um debate do autor com Jung e com Bleuler, com quem Freud investigava esse assunto. É desse debate que nascerá um segundo neologismo, este de Bleuler, em1907. É deste autor a criação do termo autismo, que repousará em uma enciclopédia de psiquiatria até 1940, quando será retomado por Kanner para designar algo que observava em certas crianças.

3. Cf. "todo delírio de perseguição na demência precoce contém implicitamente um delírio de grandeza"; esta fórmula é de Abraham e foi ratificada por Freud: "As ideias de Abraham foram mantidas e tornaram-se mesmo os fundamentos de nossa tomada de posição face às psicoses".

4. Segundo a formulação lacaniana: "O significante é aquilo que representa o sujeito para um outro significante".

5. No original, actant. ser ou objeto que completa a ação expressa pelo verbo. Syn: agente, sujeito. jfalek@usp.br

Avenida Arruda Botelho, 570, apto. 62 05466-000 - São Paulo- SP - Brasil. 